\title{
Efficacy of amoxycillin versus amoxycillin/clavulanate in acute exacerbations of chronic pulmonary obstructive disease in primary care
}

\author{
Carl Llor' \\ Silvia Hernández' \\ Anna Ribas ${ }^{2}$ \\ Carmen Álvarez ${ }^{3}$ \\ Josep Maria Cots ${ }^{4}$ \\ Carolina Bayona ${ }^{5}$ \\ Isabel González ${ }^{6}$ \\ Marc Miravitlles ${ }^{7}$ \\ BRAMOX Study Group \\ 'Primary Care Centre Jaume I, \\ Tarragona, Spain; ${ }^{2}$ Primary Care \\ Centre Santa Eugènia de Berga, \\ Spain; ${ }^{3}$ Primary Care Centre Manlleu, \\ Spain; ${ }^{4}$ Primary Care Centre La \\ Marina, Barcelona, Spain; ${ }^{5}$ Primary \\ Care Centre Valls, Spain; ${ }^{6}$ Primary \\ Care Centre Maragall, Barcelona, \\ Spain; ${ }^{7}$ Pneumology Department. \\ Institut Clínic del Tòrax (IDIBAPS), \\ Hospital Clínic, Barcelona, CIBER \\ de Enfermedades Respiratorias \\ (CIBERES), Spain
}

Background: Amoxycillin/clavulanate is considered first-line treatment for ambulatory exacerbations of COPD. However, narrow-spectrum antibiotics may be as useful for mild to moderate patients.

Objective: To compare the clinical efficacy of amoxycillin versus amoxicyllin/clavulanate in exacerbations of COPD in primary care.

Methods: A randomized, double-blind, noninferiority clinical trial was carried out in eight primary care centers in Catalonia, Spain. Spirometrically-diagnosed patients older than 40 years with COPD, without criteria of hospitalization and Anthonisen's types I or II exacerbations were included. The main outcome was clinical cure at the end of treatment (EOT) visit on day 10.

Results: A total of 137 patients were enrolled in the study (68 assigned to amoxycillin and 69 to amoxycillin/clavulanate). The mean forced expiratory flow in one second was $61.6 \%$ and the mean age was 71.4 years. At EOT, $92.8 \%$ of patients in the amoxycillin/clavulanate and $90.9 \%$ in the amoxycillin group were considered clinically cured, a statistically non-significant difference. Adverse effects were observed in 11 subjects, 3 in the amoxycillin group and 8 in the amoxycillin/clavulanate group, 2 of whom required a change in treatment.

Conclusions: Amoxycillin was at least as effective clinically and as safe as amoxycilin/ clavulanate in the treatment of acute exacerbations of COPD in mild to moderate patients in primary care.

Keywords: exacerbation, chronic obstructive pulmonary disease, randomised controlled trial, amoxycillin, primary care, amoxycillin/clavulanate

\section{Introduction}

Chronic obstructive pulmonary disease (COPD) constitutes one of the principal demands of medical attention in primary care. According to local studies, it is estimated that up to $8 \%-10 \%$ of the population over 40 years of age may be affected by COPD and, in men over 65 years of age, this figure may rise to $20 \%{ }^{1}$ Exacerbations are acute episodes of an increase in respiratory symptoms that characterize the course of COPD and result in impaired quality of life, ${ }^{2,3}$ particularly in moderate patients in primary care. ${ }^{4}$ Furthermore, they accelerate the decline in lung function, ${ }^{5}$ increase health care utilization $^{6}$ and constitute the main cause of death of patients with COPD. ${ }^{7}$

Although the etiology of COPD exacerbations is not completely established, there is strong evidence that potentially pathogenic microorganisms (PPMs) are isolated in more than half of COPD patients during exacerbations. ${ }^{8}$ Another $30 \%-40 \%$ of the exacerbations of COPD have recently been shown to be attributable to viruses ${ }^{9,10}$ alone or in combination with bacteria. ${ }^{11}$ The PPMs most commonly isolated during exacerbations are aerobic bacteria, with Haemophilus influenzae being the most frequent, followed by Streptococcus pneumoniae in second place and Moraxella catarrhalis, Chlamydophila pneumoniae, Mycoplasma pneumoniae, and Pseudomonas
Correspondence: Carl Llor c. Foixarda, 95. 43008 Tarragona, Spain

Tel +34671085857

Email carles.llor@urv.cat 
aeruginosa, ${ }^{12}$ especially in more severe patients. ${ }^{13}$ Bacterial etiology should be suspected when two or more of the following criteria are present: sputum purulence, increase in breathlessness and increase in expectoration volume. ${ }^{14}$

A recent meta-analysis has shown a reduction in the risk of therapeutic failure and death in patients receiving an antibiotic compared with those receiving placebo. ${ }^{15}$ The aims of antibiotic therapy in bacterial exacerbations of COPD are: a) to reduce the rate of relapse; b) to avoid the worsening of pulmonary function and shorten the duration of the exacerbation; and c) to prolong the period between exacerbations. ${ }^{16}$ Another recent meta-analysis has demonstrated the superiority of the so-called second-line over the oldest, first-line antibiotics in reducing the rate of relapse. ${ }^{17}$ However, when deciding the antibiotic treatment for exacerbations it is also important to consider the resistance patterns of PPMs to the most commonly used antibiotics. H. influenzae has become resistant because of the production of $\beta$-lactamases. Indeed, approximately $20 \%$ of the strains of $H$. influenzae currently isolated in Spain are $\beta$-lactamase-producers. ${ }^{18}$ The prevalence of pneumococcal resistance to penicillins is approximately $20 \%$, while resistance to amoxycillin or amoxycillin/clavulanate has only been detected in less than $5 \%$ of isolates in Spain. ${ }^{18}$ In recent years, reduced spectrum penicillins have been replaced by broader spectrum penicillins in many countries. ${ }^{19}$ Indeed, the current guidelines for clinical practice recommend the use of amoxycillin/clavulanate in patients with acute exacerbations of mild to moderate COPD (500-875/125-mg three times daily for 7-10 days), since it covers the most frequent pathogens, mainly Haemophilus. ${ }^{20,21}$ Nonetheless, the administration of amoxycillin alone could be a valid alternative based on resistance profiles of PPMs isolated in primary care. ${ }^{22}$ The aim of this study was to compare the efficacy and tolerability of amoxycillin versus amoxycillin/clavulanate in patients with ambulatory exacerbations of COPD in primary care.

\section{Method}

\section{Population}

A randomized, double-blind, parallel group, clinical trial was undertaken during five winter periods from October to March, 2000 to 2005 at 8 primary care centers in Catalonia, Spain. Patients over 40 years of age were included in the study providing they had a spirometric diagnosis of COPD, ie, forced expiratory volume in one second $\left(\mathrm{FEV}_{1}\right)<80 \%$ predicted and post-bronchodilator $\mathrm{FEV}_{1}$ /forced vital capacity (FVC) ratio $<0.7 \%$ from a spirometry performed in a stable state within 12 months prior to inclusion. An exacerbation was defined according to the Anthonisen criteria ${ }^{14}$ (increased dyspnoea, increased sputum volume and purulent sputum), and only patients fulfilling Anthonisen I (all three criteria) or II (two criteria present) were enrolled. Patients were excluded from the study if they exhibited any of the following characteristics: current chronic treatment with systemic steroids at any dose, severe respiratory impairment requiring hospital referral, evidence of a new pulmonary infiltrate on chest radiography, suspected or known history of hypersensitivity to $\beta$-lactam antibiotics, administration of antibiotics within the previous four weeks, documented evidence of bronchiectasis, AIDS, another immunosuppressive condition or patients receiving treatment with immunosuppressive drugs, cystic fibrosis, or patients participating in another clinical trial within the last year. The study was approved by the Ethics and Research Committee of the Fundació Jordi Gol i Gurina (Register 00/03; Barcelona, Spain) institution that covers the studies performed in primary care in Catalonia (Spain). All the patients were duly informed of the study and written informed consent was obtained prior to their participation in the trial.

\section{Design of the study}

The patients were randomized into two treatment groups: amoxycillin (500 mg three times daily for 10 days) or amoxycillin/clavulanate $(500 / 125 \mathrm{mg}$ three times daily for 10 days). The use of antithermic drugs (acetaminophen, salicilates or ibuprofen) and oral corticoids up to a maximum of $30 \mathrm{mg}$ daily during the exacerbation were allowed on presentation of fever, pain or breathlessness. Respiratory medications for COPD were permitted during the study: short-acting and long-acting inhaled $\beta$-agonists, anticholinergics, theophyllines, inhaled corticoids or any other medication, except other antibiotics either as treatment of the exacerbation or administered chronically.

Participants were required to take the study medication for a minimum of 7 full days, unless there was clear evidence of therapeutic failure or the presence of an adverse reaction, to be included in the per protocol (PP) population. They were requested to return all the unused medication samples to the physician to check for compliance. The PP population was evaluated for efficacy. The intention-to-treat (ITT) population consisted of all patients who had taken at least one dosage of any of the study medication and was evaluated for safety.

Patients were examined at the time of entry into the study (baseline visit) and evaluation of efficacy (primary outcome) was performed at the end of treatment (EOT visit, day $10 \pm 1$ ). Clinical efficacy was also evaluated at follow-up (FU visit, day $30 \pm 4$ ). 
A complete medical history was obtained at baseline. Demographic variables such as age, sex, smoking status, the use of bronchodilator treatment, symptoms and signs, Anthonisen's type of exacerbation, lung function and concomitant diseases such as hypertension, hypercholesterolemia, diabetes mellitus, coronary heart disease, chronic renal failure and heart failure were collected.

We assessed study outcomes on the EOT and FU visits. On the EOT visit, clinical response was defined as clinical cure (resolution or sufficient improvement of the signs and symptoms of exacerbation recorded at baseline such that no additional antibacterial therapy was prescribed for the episode of acute exacerbation) or clinical failure (insufficient reduction in the signs and symptoms of infection requiring the implementation of a new antimicrobial treatment). At visit 3, the clinical response was also defined as clinical cure (continued resolution or improvement) or failure (nonresponse or reappearance of signs and symptoms and need for antibacterial therapy). In cases of clinical deterioration, the investigator initiated another antibiotic treatment according to the clinical criteria. Side effects were evaluated in the ITT population and were recorded at all visits and ranked by intensity (mild, moderate, severe or serious) and relationship to the study medication. The percentage of patients who abandoned treatment due to intolerance and the number of relapses and days with recurrence after one month of having initiated antibiotic therapy was evaluated.

\section{Statistical analysis}

The study was powered as a non-inferiority study, and the sample size was calculated in order to demonstrate that amoxycillin was not $>15 \%$ less effective than amoxycillin/ clavulanate. Sample size was based on a predictive cure rate of $85 \%$ in the amoxycillin/clavulanate group with a $15 \%$ equivalence between study arms, $\alpha: 2.5 \%$ (one-sided) and $\beta: 20 \%$. Thus, 68 patients were needed per treatment arm, including possible losses of $15 \%$. The two treatments groups were compared for efficacy using the Fisher exact test. For comparison of means \pm SD of demographic and medical characteristics of patients before study entry the Student's t-test was used. For adverse effects a Fisher exact test was utilized. Statistical differences were considered significant with a $\mathrm{p}<0.05$.

\section{Results}

A total of 173 potential eligible patients were screened for inclusion. Of these, 36 were excluded as they did not fulfil the inclusion criteria (29 cases did not have recent spirometry), refused to take part in the study or their follow-up data were incomplete (Figure 1). One hundred thirty-seven patients were eligible for randomization and 135 (66 patients in the amoxycillin arm and 69 patients in the amoxycillin/clavulanate arm) fulfilled all the criteria for the analysis of efficacy and formed the PP population. The mean age was 71.4 years (SD: 8.5 years). A moderate COPD (GOLD stage II; $\mathrm{FEV}_{1}$ between $50 \%$ and $80 \%$ predicted) was observed in 103 patients and a severe COPD (GOLD III; $\mathrm{FEV}_{1}$ between $30 \%$ and $50 \%$ predicted) was found in the remaining 32 patients. As shown in Table 1, no statistically significant differences were observed between the two treatment arms with regard to the main variables analyzed. However, patients assigned to the amoxycillin group presented slightly better pulmonary function than those treated with amoxycillin/clavulanate, although the differences were not statistically significant. On the other hand, more patients with coronary heart disease were included in the amoxycillin group (38.2\% and $20.3 \%$, respectively). The mean $\mathrm{FEV}_{1}$ was $61.6 \%$ (SD: $11.5 \%$ ) and the mean number of exacerbations during the previous year was of 1.6 (SD: 1.5). An increase in sputum volume (86.9\%) and dyspnoea $(73.7 \%)$ were the most relevant clinical data. $62.8 \%$ presented an increase in the purulence of the sputum. The majority of patients $(71.5 \%)$ had a type II acute exacerbation of COPD.

A total of 133 patients took at least 7 days of antibiotic therapy $(98.5 \%)$. On the EOT visit, 60 patients assigned to receive amoxycillin were cured $(90.9 \%)$ compared to 64 $(92.8 \%)$ in the amoxycillin/clavulanate group (Figure 2). No statistically significant differences were found. Treatment failed in nine patients ( 6 in the amoxycillin group and 3 in the amoxycillin/clavulanate group) with a change in antibiotic being necessary (Table 2). Two additional patients assigned to the amoxycillin/clavulanate group presented drug-related adverse events and required a different antibacterial treatment. These two patients took the medication less than seven days. Although the sample size of the study does not allow for reliable subgroup statistical analysis, we did not find significant differences in clinical efficacy between treatment arms in either patients with type I (amoxycillin/ clavulanate $89.5 \%$, amoxicyllin $85 \%$ ) or with type II exacerbations (amoxycillin/clavulanate 94\%, amoxicyllin 93.7\%). As shown in Table 2, clinical failure was observed in patients who presented a lower $\mathrm{FEV}_{1}$, more comorbidities and were older than the mean of the group. All failures were cured after changing the antibiotic. Adverse events were observed in 11 subjects, 10 with gastrointestinal symptoms. Eight patients $(11.6 \%)$ receiving amoxycillin/clavulanate experienced 
(n: 173)

Potential eligible patients

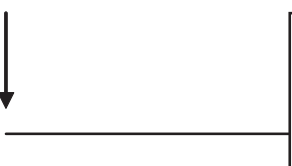

No spirometry (n: 29)

Type III exacerbations (n: 3 )

Antibiotics taken previously (n: 2)

Participants who fulfilled

inclusion criteria (n: 139)

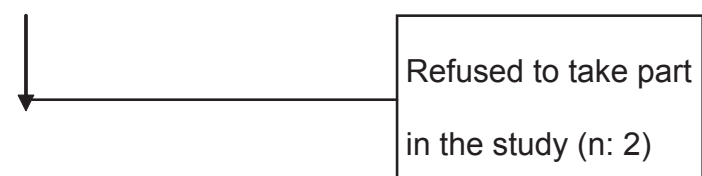

Patients eligible for

randomization (n: 137)

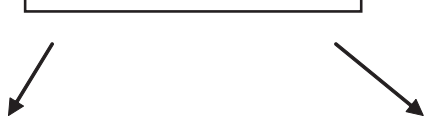

Amoxycillin

(n: 68)

Amoxycillin/clavulanate

(n: 69)

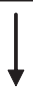

Lost to follow-up:

n: 1 did not return the unused

medication sample
$\mathrm{n} 1$ did not attend the scheduled
visit

medication sample
$\mathrm{n} 1$ did not attend the scheduled
visit

medication sample
$\mathrm{n} 1$ did not attend the scheduled
visit

Lost to follow-up

n: 0
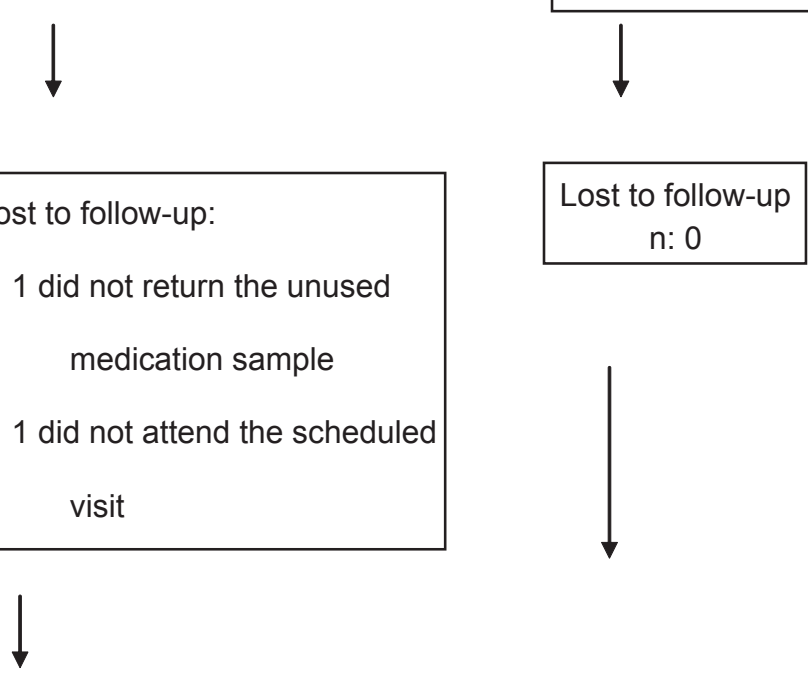

Analyzed

Analyzed

(n: 66)

(n: 69)

Figure I Trial profile flow chart. 
Table I Baseline characteristics of the patients participating

\begin{tabular}{|c|c|c|c|}
\hline & Amoxycillin & $\begin{array}{l}\text { Amoxycillin/ } \\
\text { clavulanate }\end{array}$ & Total \\
\hline Number of patients & 68 & 69 & 137 \\
\hline Mean age, years (SD) & $71.9(8.6)$ & $70.8(8.5)$ & $71.4(8.5)$ \\
\hline Age range, years & $53-88$ & $49-85$ & $49-88$ \\
\hline Male (\%) & $53(77.9)$ & $56(8 \mid .2)$ & $109(79.6)$ \\
\hline Mean $\mathrm{FEV}_{1}, \%$ (SD) & $62.9(11.0)$ & $60.4(11.9)$ & $61.6(11.5)$ \\
\hline $\mathrm{FEV}_{1}$, range, $\%$ & $39-79$ & $32-78$ & $32-79$ \\
\hline \multicolumn{4}{|l|}{ Smoking status } \\
\hline Current smoker, n (\%) & $15(22.1)$ & $12(17.4)$ & $27(19.7)$ \\
\hline Former smoker, n (\%) & $53(77.9)$ & $57(82.6)$ & $110(80.3)$ \\
\hline Never smoked, n (\%) & 0 & 0 & 0 \\
\hline $\begin{array}{l}\text { Number of exacerbations } \\
\text { in the previous year, } n(S D)\end{array}$ & $1.69(1.3)$ & $1.56(1.7)$ & $1.63(1.5)$ \\
\hline \multicolumn{4}{|l|}{ Symptoms } \\
\hline Temperature $>38^{\circ} \mathrm{C}, \mathrm{n}(\%)$ & $10(14.7)$ & $7(10.1)$ & $17(12.4)$ \\
\hline Increase in dyspnoea, $\mathrm{n}(\%)$ & $48(70.6)$ & $53(76.8)$ & I0I (73.7) \\
\hline Increase in sputum volume, $\mathrm{n}(\%)$ & $63(92.6)$ & $56(8 \mid .2)$ & $119(86.9)$ \\
\hline Sputum purulence, n (\%) & $39(57.4)$ & $47(68.1)$ & $86(62.8)$ \\
\hline \multicolumn{4}{|l|}{ Anthonisen classification } \\
\hline I type, n (\%) & $20(29.4)$ & $19(27.5)$ & $39(28.5)$ \\
\hline II type, n (\%) & $48(70.6)$ & $50(72.5)$ & $98(71.5)$ \\
\hline \multicolumn{4}{|l|}{ Comorbidities } \\
\hline High blood pressure, n (\%) & $35(5 \mid .5)$ & $38(55.9)$ & $73(53.3)^{*}$ \\
\hline Diabetes, n (\%) & $9(13.2)$ & $7(10.1)$ & $16(11.7)$ \\
\hline Hypercholesterolemia, n (\%) & $14(20.6)$ & $18(26.1)$ & $32(23.4)$ \\
\hline Coronary heart disease, $\mathrm{n}(\%)[\#]$ & $26(38.2)$ & $14(20.3)$ & $40(29.2)$ \\
\hline Heart failure, n (\%) & $10(14.7)$ & $4(5.8)$ & $14(10.2)$ \\
\hline $\begin{array}{l}\text { Uptake of pneumococcal } \\
\text { vaccine, } n(\%)\end{array}$ & $50(73.5)$ & $49(7 \mid .0)$ & $99(72.3)$ \\
\hline \multicolumn{4}{|l|}{ Drugs taken } \\
\hline Anticholinergics $\mathrm{n},(\%)$ & $33(48.5)$ & $35(50.7)$ & $68(49.6)$ \\
\hline Long-acting inhaled $\beta$ agonists $\mathrm{n},(\%)$ & $29(42.6)$ & $30(43.5)$ & $59(43.1)$ \\
\hline Short-acting inhaled $\beta$ agonists $\mathrm{n},(\%)$ & 61 (89.7) & $59(85.5)$ & $120(87.6)$ \\
\hline Inhaled glucocorticoids, n (\%)[\#\#] & $52(76.5)$ & $38(55.1)$ & $90(65.7)$ \\
\hline Oral glucocorticoids, n (\%) & $21(30.9)$ & $19(27.5)$ & $40(29.2)$ \\
\hline Theophyllines, n (\%) & $2(2.9)$ & $4(5.8)$ & $6(4.4)$ \\
\hline
\end{tabular}

Abbreviations: $\mathrm{FEV}_{1}$, forced expiratory volume in one second; Anthonisen type I, all three criteria present (increased dyspnoea, increased sputum volume, and purulent sputum); Anthonisen type II, only two criteria present.

Notes: $\# p<0.05 ; \# \# p<0.01$.

gastrointestinal side effects ( 2 reports of diarrhea) leading to a change in antibiotic in 2 cases. On the other hand, 3 patients (4.4\%) presented intolerance to amoxycillin (gastrointestinal disturbances and itching) although it was not necessary to substitute the antimicrobial.

Similar results were observed in both groups on the FU visit on day 30 . Of the patients cured at day 10,57 patients in the amoxycillin arm (95\%) and 62 patients assigned to amoxicillin/clavulanate treatment $(96.9 \%)$ were still considered to be clinically cured (Figure 2).

\section{Discussion}

The results of our study show that treatment with amoxycillin is not inferior to amoxycillin/clavulanate regarding clinical 


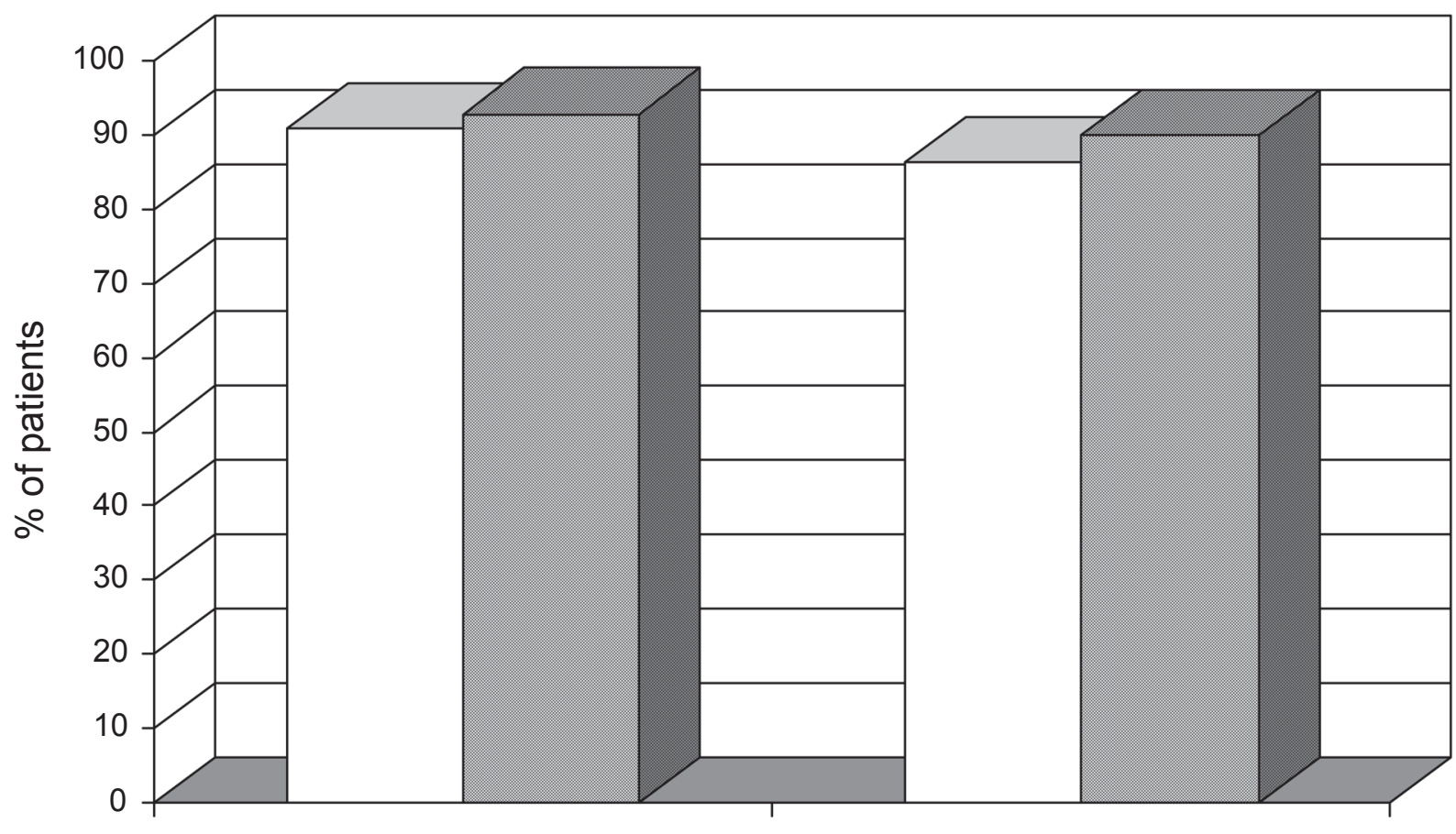

Day 10

Day 30

\section{$\square$ Amoxycillin $\square$ Amoxycillin/clavulanate}

Figure 2 Clinical cure at days 10 and 30 in the evaluable patients with COPD exacerbation.

efficacy at 10 and 30 days in patients with types I and II ambulatory exacerbations of moderate COPD in primary care. Similarly, both drugs were well tolerated, but with a higher incidence of gastrointestinal adverse events in the group treated with amoxicyllin/clavulanate.

Our study has some limitations. Although we acknowledge the importance of the assessment of bacterial eradication in antimicrobial trials, we were not able to investigate the bacterial etiology of the exacerbations and the eradication rates after antimicrobial treatment. Since the trial was performed in primary care, these microbiological evaluations were not readily available in the centers participating in the study. This situation reflects current clinical practice, in which no microbiological analysis of sputum is performed in patients with exacerbations of $\mathrm{COPD}^{23}$ and current guidelines do not recommend the systematic analysis of sputum

Table 2 Failures observed on day 10 after the initiation of antibiotic therapy

\begin{tabular}{lllll}
\hline Antibiotic & $\begin{array}{l}\text { Anthonisen } \\
\text { classification }\end{array}$ & Age (yr) & FEV (\%) & Comorbid conditions \\
\hline Amoxycillin & Type I & $8 I$ & 43 & High blood pressure, heart failure \\
Amoxycillin & Type I & 80 & 65 & High blood pressure, coronary heart disease \\
Amoxycillin & Type II & 76 & 45 & High blood pressure, coronary heart disease \\
Amoxycillin & Type II & 83 & 65 & Hypercholesterolemia, coronary heart disease \\
Amoxycillin & Type II & 74 & 39 & None \\
Amoxycillin & Type I & 79 & 44 & High blood pressure \\
Amoxycillin/clavulanate & Type I & 74 & 32 & High blood pressure, diabetes mellitus, \\
& & & & hypercholesterolemia, coronary heart failure \\
Amoxycillin/clavulanate & Type II & 85 & 69 & High blood pressure \\
Amoxycillin/clavulanate & Type I & 66 & 51 &
\end{tabular}

Notes: Two patients assigned to amoxycillin/clavulanate discontinued the antibiotic due to adverse effects and were also considered as therapeutic failure. 
to direct antimicrobial therapy. ${ }^{20,21}$ However, the lack of microbiological data does not invalidate the conclusions of the study. The landmark study on antibiotics in COPD was performed based exclusively on clinical efficacy, ${ }^{14}$ as were other posterior studies on clinical efficacy of antimicrobials in this indication. ${ }^{24,25}$ Furthermore, the diagnostic yield of the microbiological analysis of sputum is low, and in most clinical trials no more than $30 \%$ to $40 \%$ of cases have a sputum sample with a significant growth of a PPM, which is valid for analysis of microbiological efficacy. ${ }^{26-28}$ Another limitation is the lack of statistical power to show the superiority of one antibacterial treatment over the other. Clinicians require comparative data of the treatment options available to choose the best and safest for each patient. ${ }^{29}$ However, superiority trials require a large sample size that is beyond the possibilities of our study. To circumvent this problem, a recent meta-analysis has demonstrated the clinical superiority of second-line antibiotics compared with oldest, first-line antibiotics in exacerbations of COPD ${ }^{17}$ Nevertheless, this meta-analysis did not consider the efficacy of individual antibiotics compared one by one and the inferior results observed with the first-line antibiotics may not be related to all the products in the class. Therefore, we believe that showing noninferiority of the most prescribed first-line antibiotic, amoxycillin, compared with one of the most prescribed second-line antibiotic, ie, amoxycillin/clavulanate, provides relevant complementary information for practicing physicians in primary care. ${ }^{30}$

On the other hand, our study has several strengths. In contrast with other antibiotic trials, our population consisted of patients with well characterized COPD diagnosed by spirometry. On many occasions clinical trials do not require this condition and diagnosis of chronic bronchitis is enough to include patients in the study. ${ }^{26,27,31}$ The diagnosis of chronic bronchitis is very unreliable in primary care ${ }^{32}$ and this is demonstrated by the frequent inclusion of patients who are younger than 40 years and a significant proportion of never smokers. ${ }^{26,31}$ Showing noninferiority between two different antibiotics in this population is easy and has a very low clinical relevance because the rate of relapse, even without antibiotics, is very low. ${ }^{29,33}$

At day 10 of treatment, $92.8 \%$ of patients in the amoxycillin/clavulanate group and $90.9 \%$ of patients in the amoxycillin group were considered clinically cured, a statistically nonsignificant difference. More side effects were observed with amoxycillin/clavulanate even though most of these drug-related side effects in both treatment groups were mild. Antibiotic-associated diarrhea is a common complication of antibiotic treatment and can be triggered by any antibiotic but is particularly high with amoxycillin/ clavulanate. ${ }^{34}$ Clavulanic acid is known to be the cause of this adverse effect and the incidence of diarrhoea may be reduced when a lower daily dose of clavulanic acid is given. ${ }^{35}$ In our study, only two patients assigned to amoxycillin/clavulanate discontinued the antibiotic due to diarrhea. The number of changes in antibiotic was similar in the two groups, with six cases among those receiving amoxycillin due to clinical failure and five among those treated with amoxycillin/ clavulanate. In the latter, three were due to therapeutic failure and two because of intolerance to the antibiotic. In primary care it is important to take the clinical effectiveness of the therapeutic regimens into account but it also important to know the safety and possible compliance to be achieved with the treatment. As is shown in the present survey, the greater intolerance found with the use of clavulanic acid did not allow correct compliance in all patients.

Evidence related to the efficacy of amoxycillin in COPD exacerbations is controversial. Georgopoulos and colleagues ${ }^{36}$ compared the efficacy and safety of amoxycillin at different doses and observed a clinical success rate of $85.6 \%$ using $500 \mathrm{mg}$ three times daily. Mertens and colleagues ${ }^{37}$ found no differences in clinical success between amoxycillin and azithromycin. On the other hand, Adams

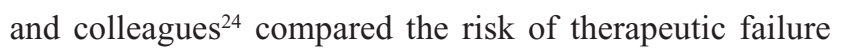
between amoxycillin and other agents such as amoxycillin/ clavulanate, cephalosporins, and quinolones, and observed that treatment of the exacerbation with amoxycillin was associated with an increased relative risk of failure of 3.37 compared with the other antimicrobial agents. However, their population consisted of more severe patients discharged from the emergency room of a Veterans Hospital in the US. It is of note that our results cannot be extrapolated to more severe COPD patients attended in hospital. Similarly, we cannot rule out that amoxycillin/clavulanate could be superior to amoxycillin in more severe patients with a higher risk to be infected by resistant strains of PPMs. Previous studies have suggested that patients with severe airflow obstruction should receive broad-spectrum antibiotics active against $P$. aeruginosa (ERS, SEPAR). Utilization of aminopenicillins, to which $P$. aeruginosa and $M$. catarrhalis are frequently resistant, should be avoided in these patients with recurrent exacerbations and $\mathrm{FEV}_{1}$ below 35\% predicted. ${ }^{13,38,39}$ An increasing number of isolates of beta-lactamase-producing strains of $H$. influenzae has been reported over the last years. Nevertheless, in a continuing surveillance study carried out in 26 countries, examining the susceptibility of pathogens 
involved in adult community-acquired respiratory tract infections, mean beta-lactamase production was observed in $16.9 \%$ of these strains. ${ }^{40}$ In a recent study, this percentage was even lower in another survey with isolates of twenty countries in Europe, eastern Asia and southern Africa. ${ }^{41}$ Our study was carried out in Spain, one of the leading countries with a higher production of beta-lactamases, of approximately $20 \%$. Furthermore, $5 \%$ of pneumococcal strains are resistant to amoxycillin in our country, compared with most countries where the resistance rate to this aminopenicillin is uncommonly found. However, a recent work reported $13 \%$ of resistance in South Africa. ${ }^{42}$ Our study was carried out in a country with one of the highest resistance rates and therefore the main result highlighting the noninferiority of amoxicillin may be extrapolated to other countries with even lower rates of resistance.

The therapeutic failures observed in our study presented a lower $\mathrm{FEV}_{1}$, more chronic comorbid conditions such as hypertension, diabetes or coronary heart disease and were older than 66 years. These findings concur with the risk factors described for clinical failure ${ }^{24,43-45}$ and suggest that these patients must be closely followed.

Amoxycillin has been the classical antibiotic treatment for exacerbations of chronic bronchitis and COPD. However, for several years it has been recommended that this drug be administered in association with clavulanic acid because of the resistance rates of Haemophilus and pneumococci. ${ }^{20,21}$ Nonetheless, COPD patients attended by family physicians usually have mild or moderate pulmonary disease and are often cured with antibiotics with a narrower antibacterial spectrum than that recommended in the current guidelines. In addition, amoxycillin/clavulanate is more expensive and, as other broad-spectrum antibiotics, is associated with a higher spread of resistant strains in the community. If the results of this study are replicated in other large-scale clinical trials, the current recommendations of antimicrobial treatment for mild to moderate patients should be reconsidered.

\section{Acknowledgments}

The Catalan Society of Family Medicine provided funding to the Pharmacy Department of the Hospital Joan XXIII (Tarragona) for preparation of the double blind medication used in the trial. No funding was obtained from any pharmaceutical industry. The authors have no conflicts of interest to declare in relation to this manuscript.

We wish to acknowledge the contribution of the following investigators to this study. BRAMOX Study Group members: Xabier Ansa (Primary Care Centre Sant Pere i Sant
Pau, Tarragona), Montse Bonamaison (Primary Care Centre Manlleu), Marta Cereceda (Primary Care Centre Manlleu), Joan Deniel (Primary Care Centre Manlleu), Jordi Espina (Primary Care Centre Manlleu), Jordi Espinàs (Primary Care Centre Santa Eugènia de Berga), Teresa Ezquerra (Primary Care Centre Manlleu), Josep M. Gifré (Primary Care Centre Santa Eugènia de Berga), Ferran Grifoll (Primary Care Centre Sant Pere i Sant Pau, Tarragona), M. Mar Pedrerol (Primary Care Centre Manlleu), Albert Planes (Primary Care Centre Santa Eugènia de Berga), Xavier Pujol (Primary Care Centre Manlleu), Montserrat Ribas (Primary Care Centre Manlleu), Anna Rodríguez (Primary Care Centre Santa Eugènia de Berga), Rosa M. Salla (Primary Care Centre Santa Eugènia de Berga), Jordi Valldosera (Primary Care Centre Sant Pere i Sant Pau, Tarragona), Meritxell Vilajoana (Primary Care Centre Santa Eugènia de Berga), and Maria Vilamú (Primary Care Centre Manlleu).

\section{References}

1. Sobradillo Pena V, Miravitlles M, Gabriel R, et al. Geographical variations in prevalence and underdiagnosis of COPD. Results of the IBERPOC multicentre epidemiological study. Chest. 2000;118:981-9.

2. Seemungal TAR, Donaldson GC, Paul EA, et al. Effect of exacerbation on quality of life in patients with chronic obstructive pulmonary disease. Am J Respir Crit Care Med. 1998;157:1418-22.

3. Miravitlles M, Ferrer M, Pont A, et al. the IMPAC study group. Exacerbations impair quality of life in patients with chronic obstructive pulmonary disease. A two-year follow-up study. Thorax. 2004;59:387-95.

4. Llor C, Molina J, Naberan K, et al. on behalf of the EVOCA study. Exacerbations worsen the quality of life of chronic obstructive pulmonary disease patients in primary healthcare. Int J Clin Pract. 2008;62:585-92.

5. Donaldson GC, Seemungal TA, Bhowmik A, et al. Relationship between exacerbation frequency and lung function decline in chronic obstructive pulmonary disease. Thorax. 2002;57:847-52.

6. Miravitlles M, Murio C, Guerrero T, et al. on behalf of the DAFNE study group. Pharmacoeconomic evaluation of acute exacerbations of chronic bronchitis and COPD. Chest. 2002;121:1449-55.

7. Burrows B, Bloom JW, Traver GA, et al. The course and prognosis of different forms of chronic airways obstruction in a sample from the general population. N Engl J Med. 1987;317:1309-14.

8. Monsó E, Ruiz J, Rosell A, et al. Bacterial infection in chronic obstructive pulmonary disease. A study of stable and exacerbated outpatients using the protected specimen brush. Am J Respir Crit Care Med. 1995;152(4 Pt 1):1316-620.

9. Seemungal TA, Harper-Owen R, Bhowmik A, et al. Respiratory viruses, symptoms, and inflammatory markers in acute exacerbations and stable chronic obstructive pulmonary disease. Am J Respir Crit Care Med. 2001;164:1618-23.

10. Rohde G, Wiethege A, Borg I, et al. Respiratory viruses in exacerbations of chronic obstructive pulmonary disease requiring hospitalisation: a case-control study. Thorax. 2003;58:37-42.

11. Papi A, Bellettato CM, Braccioni F, et al. Infections and airway inflammation in chronic obstructive pulmonary disease severe exacerbations. Am J Respir Crit Care Med. 2006;173:1114-21.

12. Miravitlles M. Epidemiology of chronic obstructive pulmonary disease exacerbations. Clin Pulm Med. 2002;9:191-7.

13. Miravitlles M, Espinosa C, Fernández-Laso E, et al. Study Group of Bacterial Infection in COPD. Relationship between bacterial flora in sputum and functional impairment in patients with acute exacerbations of COPD. Chest. 1999;116:40-6. 
14. Anthonisen NR, Manfreda J, Warren CPW, et al. Antibiotic therapy in exacerbations of chronic obstructive pulmonary disease. Ann Intern Med. 1987;106:196-204.

15. Puhan MA, Vollenweider D, Latshang T, et al. Exacerbations of chronic obstructive pulmonary disease: When are antibiotics indicated? A systematic review. Respir Res. 2007;8:8-30.

16. Miravitlles M. Exacerbations of chronic obstructive pulmonary disease: when are bacteria important? Eur Respir J. 2002;20(Suppl 36):9s-19s

17. Dimopoulos G, Siempos II, Korbila IP, et al. Comparison of first-line with second-line antibiotics for acute exacerbations of chronic bronchitis. A metaanalysis of randomized controlled trials. Chest. 2007;132:447-55.

18. Pérez-Trallero E, García de la Fuente C, García-Rey C, et al. Spanish Surveillance Group for Respiratory Pathogens. Geographical and ecological analysis of resistance, coresistance, and coupled resistance to antimicrobials in respiratory pathogenic bacteria in Spain. Antimicrob Agents Chemother. 2005;49:1965-72.

19. Ferech M, Coenen S, Malhotra-Kumar S, et al. ESAC Project Group. European surveillance of antimicrobial consumption (ESAC): outpatient antibiotic use in Europe. J Antimicrob Chemother. 2006;58:401-7.

20. Woodhead M, Blasi F, Ewig S, et al. Guidelines for the management of adult lower respiratory tract infections. Eur Respir J. 2005;26:1138-80.

21. Miravitlles M, Monsó E, Mensa J, et al. Antimicrobial treatment of exacerbation in chronic obstructive pulmonary disease: 2007 consensus statement. Arch Bronconeumol. 2008;44:100-8

22. Llor C, Cots JM, Herreras A. Bacterial etiology of chronic bronchitis exacerbations treated by primary care physicians. Arch Bronconeumol. 2006;42:388-93

23. Johnson PH, Macfarlane JT, Humphreys H. How is sputum microbiology used in general practice? Respir Med. 1996;90:87-8.

24. Adams SG, Melo J, Luther M, et al. Antibiotics are associated with lower relapse rates in outpatients with acute exacerbations of COPD. Chest. 2000;117:1345-52.

25. Miravitlles M, Llor C, Naberan K, et al. Variables associated with recovery from acute exacerbations of chronic bronchitis and chronic obstructive pulmonary disease. Respir Med. 2005;99:955-65.

26. Wilson R, Allegra L, Huchon G, et al. Short and long-term outcomes of moxifloxacin compared to standard antibiotic treatment in acute exacerbations of chronic bronchitis. Chest. 2004;125:953-64

27. Alvarez-Sala JL, Kardos P, Martinez-Beltran J, et al. Clinical and bacteriological efficacy in treatment of acute exacerbations of chronic bronchitis with cefditoren-pivoxil versus cefuroxime-axetil. Antimicrob Agents Chemother. 2006;50:1762-7.

28. Wilson R, Kubin R, Ballin I, et al. Five day moxifloxacin therapy compared with 7 day clarithromycin therapy for the treatment of acute exacerbations of chronic bronchitis. J Antimicrob Chemother. 1999;44:501-13.

29. Miravitlles M, Torres A. No more equivalence trials for antibiotics in exacerbations of COPD, please, Chest. 2004;125:811-13.

30. Miravitlles M. Do we need new antibiotics for treating exacerbations of COPD? Ther Adv Respir Dis. 2007;1:61-76.

31. Bobadilla A, Guerra S, Sherrill D, et al. How accurate is the self-reported diagnosis of chronic bronchitis? Chest. 2002;122:1234-9.
32. Chodosh S, DeAbate CA, Haverstock D, et al. Short-course moxifloxacin therapy for treatment of acute bacterial exacerbations of chronic bronchitis. Respir Med. 2000;94:18-27.

33. Evans AT, Husain S, Durairaj L, et al. Azithromycin for acute bronchitis: a randomised, double-blind, controlled trial. Lancet. 2002;359:1648-54.

34. Turck D, Bernet JP, Marx J, et al. Incidence and risk factors of oral antibiotic-associated diarrhea in an outpatient pediatric population. J Pediatr Gastroenterol Nutr. 2003;37:22-6.

35. Hoberman A, Paradise JL, Burch DL, et al. Equivalent efficacy and reduced occurrence of diarrhea from a new formulation of amoxicillin/clavulanate potassium (Augmentin) for treatment of acute otitis media in children. Pediatr Infect Dis J. 1997;16:463-70.

36. Georgopoulos A, Borek M, Ridl W; the Amoxycillin Bronchitis Study Group. Randomized, double-blind, double-dummy study comparing the efficacy and safety of amoxycillin $1 \mathrm{~g}$ bd with amoxycillin $500 \mathrm{mg}$ tds in the treatment of acute exacerbations of chronic bronchitis. J Antimicrob Chemother. 2001;47:67-76.

37. Mertens J, van Barneveld P, Asin H, et al. Double-blind randomised study comparing the efficacies and safeties of a short (3-day) course of azithromycin and a 5-day course of amoxicillin in patients with acute exacerbations of chronic bronchitis. Antimicrob Agents Chemother. 1992;36:1456-9.

38. Monsó E, García-Aymerich J, Soler N, et al. Bacterial infection in exacerbated COPD with changes in sputum characteristics. Epidemiol Infect. 2003;131:799-804.

39. Eller J, Ede A, Schaberg T, et al. Infective exacerbations of chronic bronchitis. Relation between bacteriologic etiology and lung function. Chest. 1998;113:1542-8.

40. Jacobs MR, Felmingham D, Appelbaum PC, et al. The Alexander Project Group. The Alexander Project 1998-2000: susceptibility of pathogens isolated from community-acquired respiratory tract infection to commonly used antimicrobial agents. J Antimicrob Chemother. 2003;52:229-46.

41. Beekmann SE, Heilmann KP, Richter SS, et al. the GRASP Study. Antimicrobial resistance in Streptococcus pneumoniae, Haemophilus influenzae, Moraxella catarrhalis and group A $\beta$-haemolytic streptococci in 2002-2003 Results of the multinational GRASP Surveillance Program. Int J Antimicrob Agents. 2005;25:148-56.

42. Morrissey I, Colclough A, Northwood J. TARGETed surveillance: susceptibility of Streptococcus pneumoniae isolated from communityacquired respiratory tract infections in 2003 to fluoroquinolones and other agents. Int J Antimicrob Agents. 2007;30:345-51.

43. Ball P, Harris JM, Lowson D, et al. Acute infective exacerbations of chronic bronchitis. QJM. 1995; 88:61-8.

44. Miravitlles M, Murio C, Guerrero T; on behalf of the DAFNE Study Group. Factors associated with relapse after ambulatory treatment of acute exacerbations of chronic bronchitis. A prospective multicenter study in the community. Eur Respir J. 2001;17:928-33.

45. Wilson R, Jones P, Schaberg T, et al. Antibiotic treatment and factors influencing short and long term outcomes of acute exacerbations of chronic bronchitis. Thorax. 2006;61:337-42. 
